Proceedings

\title{
Covid -19 and self-medication in Poland
}

\author{
Marta Makowska *, Rafał Boguszewski, Michał Nowakowski and Monika Podkowińska
}

\begin{abstract}
Aim: The first wave of the Covid-19 pandemic was an event that fundamentally changed the way people live and the functioning of the health system in Poland. The study aimed to examine whether the pandemic and the associated lockdown caused Polish people to engage in more selfmedication-related behaviors. Method: An online survey of a quota sample of 1013 people was obtained, the sample being representative of the Polish adult population with respect to gender, age, place of residence (in terms of population size), province of residence, and education. The survey was carried out just after implementation of the last stage of the Polish government's defrosting process on June 6, which allowed Poles to return to a "new normality". Results: Almost half of the respondents $(45.6 \%)$ indicated that they had engaged in at least one behavior associated with inappropriate self-medication during lockdown: $17.9 \%$ had taken medication for the enhancement of physical/cognitive performance; $16.9 \%$ had taken prescription medication without consulting a doctor; $15.2 \%$ had refrained from consulting a doctor despite having worrying symptoms; $19.4 \%$ had bought prescription medications just in case they might need them in the near future; $8.3 \%$ had talked a doctor into prescribing medication; $16.6 \%$ had taken medication as a precaution against becoming ill. Unsurprisingly, Pole's self-medication-related behaviors had occurred more often before the lockdown (in the whole of their lives up to lockdown) than during the lockdown (a period of only 3 months), but such behaviors occurred in many people for the first time during the lockdown (from $7 \%$ to $15.5 \%$ ). Conclusion: The issue of self-medication requires discussion if appropriate public health programs are to be developed. The availability of doctors is still limited and there is a possibility of further lockdowns, this possibility presenting a risk that the often dangerous practice of self-medication will become more prevalent. This is probably an issue in other countries in addition to Poland.
\end{abstract}

Publisher's Note: MDPI stays neutral with regard to jurisdictional claims in published maps and institutional affiliations.

\section{(c) (i)}

Copyright: (c) 2020 by the authors. Submitted for possible open access publication under the terms and conditions of the Creative Commons Attribution (CC BY) license (http://creativecommons.org/licenses /by/4.0/).
Keywords: Poland; Covid-19; self-medication 